International Journal of Sanskrit Research 2021; 7(1): 189-192

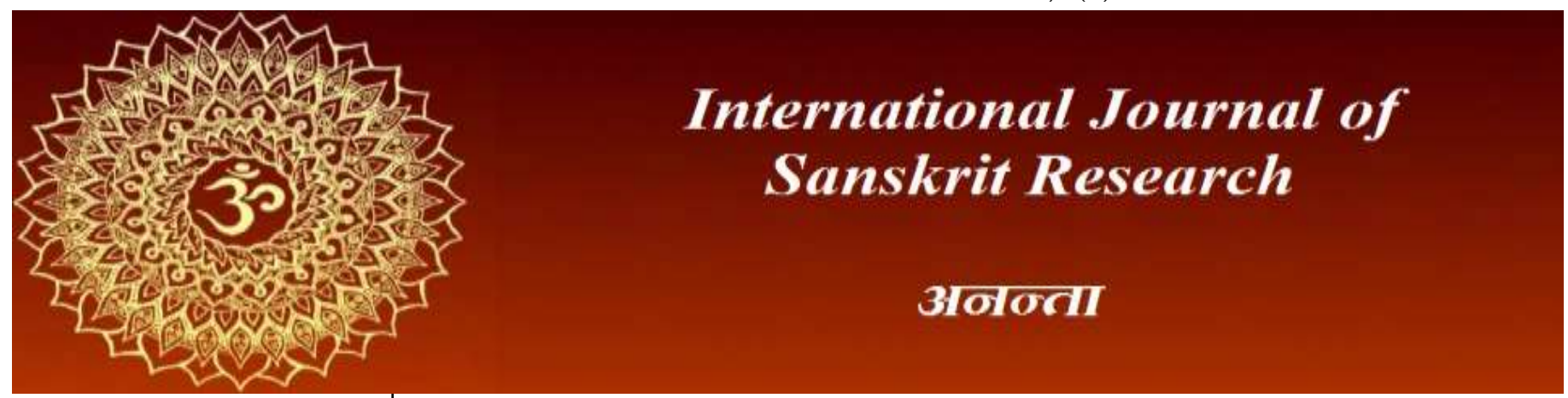

ISSN: 2394-7519

IJSR 2021; 7(1): 189-192

(C) 2021 IJSR

www.anantaajournal.com

Received: 24-10-2020

Accepted: 05-12-2020

श्रीतपनकुमारदास:

शोधच्छात्र:, विश्वभारतीविश्वविद्यालय:, पश्चिम बंगाल, भारत
Corresponding Author: श्रीतपनकुमारदास:

शोधच्छात्र:, विश्वभारतीविश्वविद्यालय:, पश्चिम बंगाल, भारत

\section{उपनिषत्सु रसभावयोरभिचिन्तनम्}

\section{श्रीतपनकुमारदास:}

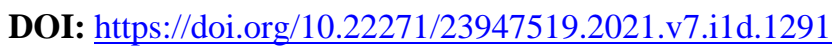

रस:

संस्कृतालंकारसाहित्यस्य प्रस्थानेषु रसप्रस्थानमेकं सुप्रसिद्धम्। भरतस्य नाट्यशास्त्रात् पण्डितराजजगन्नाथपर्यन्तं प्रस्थानस्यास्य धारैका विच्छेदविहीनतया प्रवाहितासीत् । रसो हि काव्यस्यात्मेति सिद्धान्तस्य प्रतिपादनमेवास्य मुख्यो विषयः । रस्यत आस्वाद्यत इति रसः। यद् आस्वादितमस्ति स एव रसः। काव्ये साहित्ये वा मानवीयचित्तवृत्तीनामनुभूतिवशाद् यो मानसानन्दो विद्यते, स हि रस इत्युच्यते । प्रीतिरानन्द आस्वाद: चर्वणा चमत्कारश्चेति रसस्य समार्थका एव शब्दाः। भरतमतेन अस्य लक्षणं यथा - "विभावानुभावव्यभिचारिसंयोगाद् रसनिष्पत्तिः ह्ल (ना. शा., ६/३१ गद्यम्)। अस्यार्थो भवति विभावोडनुभावो व्यभिचारिभावश्च स्थायिभावेन सह संयुक्ता: सन्तो रसं निष्पादयन्ति प्रकाशयन्ति वा । विभावादिकस्य संक्षिप्तः परिचयो निम्ने प्रदीयते -

यो रत्यादिभावान् (मानवहृदयस्य प्रधाना अप्रधाना वृत्ती:) उद्बोधयति स एव विभावः (कारणम्)। अयं च द्विविधः आलम्बनम् (नायक-नायिकादिपदार्थाः, प्रधानकारणम्) उद्दीपनं (अड्कुरितरसस्य परिपोषकम्, सहकारिकारणम्) चेति। यथा रामस्य शृङ्गररसस्य (रतिभावस्य) आलम्बनविभाव: सीता उद्दीपनविभावश्च चन्द्रोदयादिकम्।

कोधादय: स्थायिनो भावा उद्बुद्धा भवन्ति यदा तदा या: शारीरिक्यो मानसिक्यश्च प्रतिक्रिया: प्रकाश्यन्ते स एवानुभाव इति कथ्यते। मनोभावस्य बाह्य: प्रकाश एवानुभाव इति सरलार्थः। यथा - मनसि पूर्व यदि ऋोधो जागर्यते पश्चात्तर्हि शरीरस्य चक्षुरड्भं: रक्तवर्णं भवति नासिकाड़्रं च स्फीतमस्ति। इमानि शारीरिकाणि अवस्थान्तराणि एकैकस्य रसस्य एकैकविधानि सन्ति। यथा - शृड्गारे आनन्दो लज्जा कम्प इत्यादीनि करुणे च क्षोभो हताशा रोदनमित्यादीनि।

यत् काव्यस्य नाटकस्य वा नायकेषु नायिकासु चान्तिमपर्यन्त स्थिरतया विद्यते, स एव स्थायिभावः। भावोऽयं रसस्य मूलोपादानम्। यथा - रतिरभिज्ञानशकुन्तले नायकनायिकयोरन्तिमपर्यन्तं तिष्ठतीति सा रतिरेव स्थायिभावः। नाटकेऽस्मिन् शोकादिकं वर्तते, परन्तु परिशेषावधि नास्तीति शोकादिकं न स्थायिभावः। अयं स्थायिभावो नवविध इति विश्वनाथस्याभिमतम्। उत्तश्चात्र -

रतिर्हासश्च शोकश्च ऋोधोत्साहौ भयं तथा।

जुगुप्सा विस्मयश्चेत्थमष्टौ प्रोक्ता: शमोऽपि च।।

(सा. द., ३/ ८८४, पृष्ठा - १९९)

व्यभिचारिभावा नानारूपेण रसनिष्पत्तेरानुकूल्येन सश्चारिता भवन्ति। अत एते सश्चारिभावा इत्यभिधीयन्ते। इमे भावा अस्थायिनः। एते च समुद्रजलतरड्नतुल्याः। आविर्भवन्तीमे कदापि, कदापि वा तिरोहिता: सन्ति। यावद् रसपुष्ट्या प्रयोजनम्, तावदेव एषामाविर्भावो रसनिष्पत्तौ च सत्यामेव एषां तिरोभावो भवतः। एते व्यभिचारिणो भावा: संख्यया त्रयस्त्रिंशदिति भरतमतम्। त्रयस्त्रिंशति व्यभिचारिभावेषु मतिरेका। विश्वनाथो मन्यते यत्, नीतिशास्त्रानुसरणमनुमानं चेत्यादिकाद् यद् ज्ञानमुत्पद्यते, सैव मतिर्नाम। अतो ज्ञानादीषद्हास्यं धैर्य्यं सन्तोष आदरश्चेत्यादिकं जायते। यथा - अभिज्ञानशकुन्तले शकुन्तलां दृष्ट्वा दुष्यन्त उत्तवान् - "असंशयं क्षत्रपरिग्रहक्षमा .......ह (१/२०) इति। श्लोकेनानेन साधूनामभिलाषाद् दुष्यन्तस्य शकुन्तलायां क्षत्रियविवाहयोग्यता प्रतिपादितेति मतेरुदाहरणम्। मतिरियं नाटकस्य परिसमाप्तिपर्यन्तं नायकनायिकयोर्न तिष्ठतीत्यस्थायित्वम्। 
स्थायिव्यभिचारिभावद्वयस्य वर्णनात् परं नाट्यशास्त्रे सात्त्विका अष्टौ भावा विवृताः। एते भावा यथा -

स्तम्भ: स्वेदोऽथ रोमाज्चः : स्वरसादोऽथ वेपथुः।

वैवर्ण्यमश्रु प्रलय इत्यष्टौ सात्त्विका: स्मृता:।।

$$
\text { (ना. शा., ७/९४, पृष्टा - १८९) }
$$

सात्विकभावस्य लक्षणं विश्वनाथेन दत्तम् - "विकारा: सत्त्वसम्भूताः सात्त्विका: परिकीर्तिता:ह्न (सा. द., ३/ २४२, पृष्ठा - १०१) इति। अत्र सत्त्वं नाम मनःसम्भूतम्। तच्च समाहितमनस उत्पद्यते। मनःसमाहितभावात् सत्त्वनिष्पत्तिर्भवति। अन्यमनस्को जनो (नटः) रोमाज्चादिकं प्रकाशयितुं न शक्नोति। यथा - दु:खं नाम रोदनात्मकम्। तत् कथमदु:खितेन जनेन (नटेन) अभिनेतव्यम् ? पुनश्च, सुखं प्रहर्षात्मकम्। तत् कथमसुखितेन अभिनेयम् ? सात्विकभावा एव यथार्थेन दुःखितेन सुखितेन वा नटेन प्रदर्शनीयाः। यथा यथार्थदु:खितनटेन तावद् अश्रुणोऽभिनयः कर्तव्यः। यथार्थसुखभावितचित्तनटेन वा रोमाज्चः प्रदर्शनीयः। अतो यथार्थत एव तद्धावभावितनटेन भावा एते प्रदर्शयितव्या इति ते सात्तिकनाम्नाभिधीयन्ते। याथार्थ्येन नटो यदि तद्धावभावितो न भवति, तर्हि स एतेषां भावानां नैपुण्येन प्रदर्शने समर्थो नास्तीत्येव अन्यभावत एषां वैशिष्ट्यम्। काव्यस्य विभावोऽनुभावश्चेति द्वयस्य परिशेषे यद्यपि भावोऽस्ति, तथापि द्वयमेतन्न भावः। स्थायिभावो व्यभिचारिभावश्चेति द्वयं यथार्थो भाव एव (परवर्तिनि भावप्रकरणे भावलक्षणं द्रष्ट्यम्)। तत्र स्थायिभाव एव प्रधानो विभावादयश्च तमास्वाद्यमानं कुर्वन्ति। यथा - अन्नमेव प्रधानम्, व्यज्जनादिकं तस्यैव स्वादं वर्धयति च। उत्त्तज्चात्र भरतेन -

\section{यथा बहुद्रव्ययुतैर्व्यज्जनैब्बहुभिर्युतम्।}

आस्वादयन्ति भुआ्आना भत्तं भत्तविदो जनाः।।

भावाभिनयसंयुक्ता: स्थायिभावांस्तथा बुधाः।

आस्वादयन्ति मनसा तस्मात्राट्यरसाः स्मृताः।।

$$
\text { (ना. शा., ६/३ २-३३, पृष्ठा - १ ३८) }
$$

रसो रत्यादिस्थायिभावानामाधारेणैव परिकल्पित आसीत्। भावहीनो रसो नास्ति रसवर्जितश्च भावो न वर्तते। एतयोरथ सार्थकता परस्परमपेक्षते। उत्तन्च-

न भावहीनोऽस्ति रसो न भावो रसवर्जितः।

$$
\text { (ना. शा., ६/ ३ ६, पृष्टा - ३ ३८) }
$$

\section{रसस्य संख्या}

आलंकारिकेषु रससंख्यामाश्रित्य मतानैक्यं दृश्यते। तेषु नाट्यशास्त्रकारेण भरतेन रसा अष्टौ समुल्लिखिता:। उत्तज्च -

शृदुगरहास्यकरुणा रौद्रवीरभयानकाः।

बीभत्साद्दुतसंज्ञौ चेत्यष्टौ नाट्ये रसा: स्मृताः।।

$$
\text { (ना. शा., ६/ १५, पृष्ठा - १३३ ) }
$$

उत्तरसाष्टकं स्वीकृतं धनज्जयेन धनिकेन च (दशरूपकम् - ४/४३-४४, अवलोक:)।

अभिनवगुप्तो मम्मटो जगन्नाथश्च नवमरसरूपेण शान्तं स्वीकृतवन्तः।

विश्वनाथाचार्यो दशमरसत्वेन वत्सलं परिगृहीतवान् - " वत्सलश्च रस इति तेन स दशमो रस:ह्त (सा. द., ३/ २ ३ १, पृष्ठा - १४८)।
एवमेव रसविस्तार आलंकारिकेषु यथा दृश्यते, तथा रसानां प्राधान्यमधिकृत्य रससङ्कोचनमपि परिलक्ष्यते - शृङ्गारो मुख्यो रस इति मतिर्भोजस्य, रूपगोस्वामी भक्तिप्राधान्यं स्वीकृतवान्, भवभुतिना करुणस्य प्रधानता स्वीकृता, अभिनवगुप्तो मोक्षस्य परमपुरुषार्थत्वात् शान्तं मुख्यतया विवेचितवान् (लोचनटीका, ध्वन्यालोक: ३/ २६, पृष्ठा - १८६), विश्वनाथात् पूर्ववर्तिना श्रीमन्नारायणपादेन चाद्युत एव प्राधान्येनाभ्युपेतो रसे सर्वत्र चमत्कारानुभूतिवशात् (सा. द., ३/२ वृत्ति:, पृष्ठा - ४२)।

ब्रह्मास्वादसहोदर एष रसो यद्यपि सूक्ष्मतया एक एव, तथाप्युपचारदृष्टिवशात् (व्यवहारप्रयोजनात्) शृङुगरादिनानाभावेन स वर्णितोऽभवत्।

\section{उपनिषत्सु रसचिन्तनम्}

ब्रह्नज्ञान मोक्षश्चैव उपनिषदामालोच्यो विषयः। अत एतासु प्रधानरूपेण शान्तरसो विद्यते। परन्तु ब्रह्लणोऽज्ञेयता सर्वव्यापिता शक्तिमत्ता विलक्षणता सर्वनियन्तृता चेत्यादीनां वैचित्रेण प्रतिपादनार्थमुपनिषत्सु तावद् अद्धुतोऽपि समायातः।

\section{शान्तरस:}

संस्कृतकाव्यतत्त्वसमीक्षायां शान्तरसोऽतीव वितर्कितो विषय एक: । तत्र कालिदासमहाकविरष्टरसविलक्षणं शान्तरसं नाभ्युपगतवान् (विक्रमोर्वशीयम्, २/१८)। काव्यनाट्ययोरुभयोरेव रसोऽयं जगन्नाथेन प्रतिपत्नो धनज्जयेन च नाट्ये शान्तरसं नाड्भोकृत्य काव्ये एवायं गृहीतः ।

न केवलं शान्तरस एव, अपि त्वस्य स्थायिभावेऽपि साहित्यमीमांसकेषु मतभेदो विद्यते - कोऽपि वा सर्वचित्तवृत्तिप्रशमम् (अभिनवः), कोऽपि वा सम्यग्ज्ञानम् (रुद्रट:), कश्चिद्वा निर्वेदम् (अभिनवो मम्मटश्च), कश्चन वा निर्विशेषचित्तवृत्तिम् (अभिनव:), अन्य: कोऽपि वा तृष्णाक्षयसुखम् ( आनन्दवर्धन: ), कश्चन वा धृतिम् ( भोजः) शान्तरसस्य स्थायिभावरूपेण समुल्लिखितवान्।

यत्र न सुखं न दु:खं न द्वेषो न मात्सर्य सर्वभूतेषु च समता विद्यते, स एव शान्तरस: । रसस्यास्य लक्षणं विश्वनाथेनैवं संप्रदत्तम् -

शान्त: शमस्थायिभाव उत्तमप्रकृतिर्मतः ।

कुन्देन्दुसुन्दरच्छाय: श्रीनारायणदैवतः ।।

अनित्यत्वादिनाशेषवस्तुनिःसारता तु या ।

परमात्मस्वरूपं वा तस्यालम्बनमिष्यते ।।

पुण्याश्रमहरिक्षेत्रतीर्थरम्यवनादयः ।

महापुरुषसझुनद्यास्तस्योद्दीपनरूपिणः ।।

रोमाज्चाद्याश्चानुभावास्तथा स्युर्य्यभिचारिणः ।

निर्वेदहर्षस्मरणमतिभूतदयादय: ।।

(सा. द., ३/ २ २८, पृष्ठा - १४५-१४६)

अस्य दृष्टन्तो दर्शनीय: -

शतायुष: पुत्रपत्रान् वृणीष्व बहून् पशून् हस्तिहिरण्यमश्वान् । भूमेर्महदायतनं वृणीष्व स्वयं च जीव शरदो यावदिच्छसि ।। एतत्तुल्यं यदि मन्यसे वरं वृणीष्व वित्तं चिरजीविकां च । महाभूमौ नचिकेतस्त्वमेधि कामानां त्वा कामभाजं करोमि ।। ये ये कामा दुर्लभा मर्त्यलोके सर्वान् कामांश्छन्दतः प्रार्थयस्व । इमा रामा: सरथा: सतूर्या न हीदृशा लम्भनीया मनुष्यै: । आभिर्मत्प्रत्ताभि: परिचारयस्व नचिकेतो मरणं मानुप्राक्षी: ।। श्वोभावा मर्त्यस्य यदन्तकैतत् सर्वेन्द्रियाणां जरयन्ति तेजः। अपि सर्व जीवितमल्पमेव तवैव वाहास्तव नृत्यगीते ।। न वित्तेन तर्पणीयो मनुष्यो लफ्स्यामहे वित्तमद्राक्ष्म चेत् त्वा । 
जीविष्यामो यावदीशिष्यसि त्वं वरस्तु मे वरणीय: स एव ।। अजीर्यताममृतानामुपेत्य जीर्यन् मर्त्य: क्वधःस्थः प्रजानन् । अभिध्यायन् वर्णरतिप्रमोदान् अतिदीर्घे जीविते को रमेत ।।

$$
\text { (कठ., १/१/२३-२८) }
$$

अत्र हि यमनचिकेतसो: संवादेन सांसारिकपदार्थानामनित्यता ब्रह्मज्ञानस्य चावश्यकता चित्रिते नाम । अयमेव शान्तरसस्य आलम्बनविभावः । यमराजसड्गस्तथा तस्य (यमराजस्य) वाक्यश्रवणं चोद्दीपनविभाव एतस्य । विषयभोगे अनासक्तिरिति निर्वेद: (वैराग्यं वा - गीता, २/५२)। एष एवास्य व्यभिचारिभावः। नचिकेतसो ब्रह्मानन्दानुभूतिप्राप्तिसुखं तृष्णाक्षयसुखं वास्य स्थायिभावः। अस्य चानुभावो नचिकेतसो मन:संयम आत्मध्यानं चेति। एवमत्र शान्तरसस्य लक्षणसड्भतर्दर्शयितव्या।

\section{अन्दुतरस:}

यस्य दर्शनेन विचित्रचित्तवृत्तिरभिव्यज्यते, स एवाद्युतरस इति कथ्यते । अनेन चानन्यसाधारणरमणीयताया गभीरगोपनानन्द उपलभ्यते । अस्य लक्षणे विश्वनाथ उत्त्तवान् -

अद्दुतो विस्मयस्थायिभावो गन्धर्वदैवतः । पीतवर्णो वस्तु लोकातिगमालम्बनं मतम् ।। गुणानां तस्य महिमा भवेदुद्दीपनं पुन: ।

स्तम्भ: स्वेदोऽथ रोमाज्चगद्गदस्वरसंभ्रमा: ।।

तथा नेत्रविकाशाद्या अनुभावा: प्रकीर्तिता:।

वितर्कावेगसंभ्रान्तिहर्षाद्या व्यभिचारिणः ।।

$$
\text { (सा. द., ३/ २ २७, पृष्ठा - १४५) }
$$

अस्य दृष्टान्तो यथा -

केनेषितं पतति प्रेषितं मन: केन प्राणः प्रथमः प्रैति युक्तः ।

केनेषितां वाचमिमां वदन्ति चक्षुः श्रोत्रं क उ देवो युनक्ति ।। श्रोत्रस्य श्रोत्र मनसो मनो यद् वाचो ह वाचं स उ प्राणस्य प्राणः । चक्षुषश्चक्षुरतिमुच्य धीरा: प्रेत्यास्माल्लोकादमृता भवन्ति ।।

न तत्र चक्षर्गच्छति न वाग्णच्छति नो मन:।

न विद्मो न विजानीमो यथैतदनुशिष्यात् ।।

अन्यदेव तद्विदितादथो अविदितादधि ।

इति शुश्रुम पूर्वेषां ये नस्तद्व्याचचक्षिरे ।।

$$
\text { (केन., १/१-४) }
$$

अत्र गुरुशिष्यसंवादेन ब्रह्मतत्त्वं प्रतिपादितम्। साधारणतया मन्यते यदस्माकं मन एव स्वाधीनतया कार्य्य करोति, तस्य कोऽपि परिचालको नास्ति। बुद्धीन्द्रियसमन्वितो यो देहो वर्तते, मनो वै तं परिचालयति। शिष्य एतादृशेन साधारणविश्वासेन सन्देहं प्रकाश्य प्रश्नं कृतवान् - केन प्रेरितं मन इष्टविषयं गच्छतीति। एवं सन्देहाद् यो विचारो जायते, स हि वितर्कः। एष एवाद्युतरसस्य व्यभिचारिभावः। अथ शिष्यो गुरुसमीपाद् ज्ञातुमिष्टवान् - मनो नाम किं सत्यमेव स्वप्रतिष्ठं स्वाधीनं च ? मनो यदि केनचित् परिचालितं भवति, तर्हि स कस्तावत् ? इत्थं जिज्ञासाया उत्तरेण ज्ञायते यद् वस्तुतो मनो ब्रह्माधीनम्। एवमन्येषु इन्द्रियेषु बोध्यम्। मनआदिस्वाधीनतारूपाज्ञानतो लोकातीतवस्तुब्रह्सणो ज्ञानं भवतीति य एव चित्तविस्फार (चित्तप्रसारणं वा) उपतिष्ठते, स हि विस्मयः। अयं चाद्दुतरसस्य स्थायिभावः। यथार्थज्ञानरूपाभिप्रेतवस्तुलाभात् परं शिष्यस्य या चित्तप्रसन्नता, स हि हर्ष इति परिभाष्यते। अनुभावोऽयमेतस्य रसस्य। ब्रह्सरूपं लोकातिशयं वस्तु हि
नाम आलम्बनविभावः। श्रोत्रस्य श्रोत्रं मनसो मनश्चेति तद्ब्रह्मणो गुणमहत्त्वं तावदुद्दीपनविभाव:। अनेनैव रूपेणात्र अद्धुतरसस्य लक्षणमेलनं प्रदर्शनीयम्।

भाव:

न केवलं रसशब्देन शृझागादिकं बोध्यते, अपि तु तेन विज्ञाप्यते भावादिकमपि । उत्तज्च विश्वनाथेन -

रसभावौ तदाभासौ भावस्य प्रशमोदयौ ।

सन्धि: शवलता चेति सर्वोडपि रसनाद् रसा: ।।

$$
\text { (सा. द., ३/ २ ३ ४, पृष्ठा - १५०) }
$$

अस्ति च विश्वनाथप्रदत्तं भावलक्षणम् -

सज्चारिण: प्रधानानि देवादिविषया रतिः ।

उद्दुद्धमात्र: स्थायी च भाव इत्यभिधीयते ।।

$$
\text { (सा. द., ३/ २ ३५, पृष्ठा - १५१) }
$$

अर्थात् प्रधानभूता: सज्चारिभावा:, देवादिविषया रतिरुदुद्धमात्रस्थायिभावश्चेति त्रयं भाव इत्युच्यते । अनया दृष्ट्या उपनिषत्सु देवादिविषयकरतिरूपेण रसातिरिक्तो भावोऽपि दृश्यते । यथा -

अग्ने नय सुपथा राये अस्मान् विश्वानि देव वयुनानि विद्वान् ।

युयोध्यस्मज्जुहुराणमेनो भूयिष्ठां ते नमउत्तिं विधेम।।

$$
\text { (ईश., १८) }
$$

अग्ने, अस्मान् कर्मफलभोगाय (धनाय) शोभनमार्गेण गमय। देव! सर्वर्राणिनां कर्म चित्तवृत्तिश्च त्वया ज्ञायेते, त्वमस्मत्समीपात् कुटिलं (वज्चनात्मकम् ) पापं वियोजय (विनाशय); त्वां प्रति (तुभ्यम्) बहुनमस्कारवचनानि निवेदयामः। एवमत्र मन्त्र ऋषेरग्निविषये रतिरूपो भाव एव प्रतिपादित आसीत्।

उपर्युत्तेन दृष्टान्तनिचयेन परिस्फुट्यते यद् उपनिषत्सु शान्ताद्युतरसौ भावश्च प्राचुर्य्येण विद्यन्ते।

\section{ग्रन्थपत्जी}

1. अभिज्ञानशकुन्तलम्, सत्यनारायणचक्रवर्तिसम्पादितम्, संस्कृतपुस्तकभाण्डारतः प्रकाशितम्, कोलकाता - ६, २००८।

2. ईशादिदशोपनिषद: (शाट्करभाष्ययुता:), श्रीगोविन्दशास्त्रिसमलंकृता:, मोतीलालबनारसीदाससंस्थातः प्रकाशिता:, दिल्ली, १९६४ (प्रथमं संस्करणम्), २०१५ (षष्ठ संस्करणम्)।

3. उपनिषत्संग्रहः, पण्डितजगदीशशास्त्रिसम्पादित:, मोतीलालबनारसीदाससंस्थातः प्रकाशितः, दिल्ली, १९७० (प्रथमं संस्करणम्), २०११ (सप्तमं संस्करणम्)।

4. उपनिषद् इति वड्गभाषामयं पुस्तकम्; अतुलचन्द्रसेनेन, सीतानाथतत्त्वभूषणेन महेशचन्द्रघोषेण चानूदितं सम्पादितं च, हरफप्रकाशनीसंस्थात: प्रकाशितम्, कलकाता - ७, २००० (अखण्डं संस्करणम्)।

5. उपनिषद्ग्रन्थावली, स्वामिगम्भीरानन्दसम्पादिता, उद्बोधनकार्यालयतः प्रकाशिता, कलकाता - ३, २०१५ (खण्डत्रयम्)।

6. उपनिषदों में काव्यतत्त्व इति हिन्दीभाषामयं पुस्तकम्, कृष्णकुमारधवनमहोदयेन रचितम्, विश्वेश्वरानन्द-वैदिकशोध-संस्थानतः प्रकाशितम्, 
होशियारपुर, १९७६ (प्रथमं संस्करणम्)।

7. कठोपनिषद्, सीतानाथगोस्वामिसम्पादिता, संस्कृतपुस्तकभाण्डार इत्यतः प्रकाशिता, कलिकाता - ६, २०० २।

8. दशरूपकम्, सीतानाथ आचार्यशास्त्रिणा देवकुमारदासेन च सम्पादितम्, संस्कृतपुस्तकभाण्डारतः प्रकाशितम, कलिकाता - ६, २०१२ (अखण्डसंस्करणम्)।

9. ध्वन्यालोकः, सुबोधचन्द्रसेनगुप्तेन कालीपदभट्टाचार्येण च सम्पादितः, संस्कृत बुक डिपो इत्यतः प्रकाशितः, कलकाता - ६, २००५।

10. प्राचीन भारतीय अलंकारशास्त्रेर भूमिका इति पुस्तकम्, विष्णुपदभट्टाचार्यरचितम्, संस्कृत बुक डिपो इत्यतः प्रकाशितम्, कलकाता — ६, २००४।

11. भरतनाट्यशास्त्र (प्रथमं खण्डम्) इति वड्गभाषामयं पुस्तकम्, सुरेशचन्द्रवन्द्योपाध्यायसम्पादितम्, नवपत्र प्रकाशन इत्यतः प्रकाशितम्, कलिकाता - ७३, ९९९७।

12. रस ओ भाव इति पुस्तकम्, अशोकनाथशास्त्रिप्रणीतम्, संस्कृतपुस्तकभाण्डारतः प्रकाशितम्, कलिकाता - ६, १४०५ (वड्गन्द:)।

13. विक्रमोर्वशीयम्, संस्कृतसाहित्यसम्भार: (द्वादशं खण्डम् ), नवपत्र प्रकाशन इत्यतः प्रकाशितम, कलिकाता - ९, १९८२।

14. संस्कृत अलंकारसाहित्ये समालोचनार धारा इति पुस्तकम्, श्रीसत्यरज्अनवन्द्योपाध्यायविरचितम, संस्कृतपुस्तकभाण्डार इत्यतः प्रकाशितम्, कलिकाता - ६, २००५ (द्वितीयं संस्करणम्)।

15. साहित्यदर्पण:, अशोककुमारवन्द्योपाध्यायेन सम्पादितः, श्रीबलरामप्रकाशनीसंस्थातः प्रकाशितः, कलकाता - ६, १४१९।

16. History of Sanskrit Poetics, Susheel Kumar De (Ed.), Oriental Book Centre, Delhi - 7, 2006. 